\title{
A verdadeira história de Vladimir Herzog e 0 patético fim de Glauco Horowitz
}

The true story of Vladimir Herzog and the pathetic end of Glauco Horowitz

Jônata Gonçalves da Silva ${ }^{1}$ 


\section{Resumo}

O presente artigo tem como objetivo trazer para a reflexão e análise os fatos da vida, trajetória profissional e pessoal, e a morte do jornalista naturalizado brasileiro Vladimir Herzog. Cruelmente morto nos porões do DOI-CODI durante o período da ditadura militar. Sua morte é o principal conflito do texto dramatúrgico, censurado pelos militares na época, chamado de Patética. Escrito por João Ribeiro Chaves Neto, cunhado de Vladimir Herzog, a peça conta, por meio de metáforas, a triste história do jornalista assassinado pelo regime militar. Este artigo trata de apresentar um recorte da biografia de Herzog e de Chaves Neto, além de contar a trajetória do texto Patética durante $O$ processo de censura que ele sofreu. É importante deixar claro que o presente artigo tem o caráter de reflexão histórica e não de análise do texto. Trata-se de um campo de estudo da história do teatro brasileiro tendo como objetivo a discussão sobre a censura que atingiu grande parte do movimento artístico, além da violência sofrida pelo povo brasileiro nesses anos de chumbo. A metodologia empregada aqui foi a de buscar em várias biografias essa história e cruzar fatos e opiniões sobre o tema. Concluo que ainda há um certo conformismo e acomodamento no que diz respeito à memória do nosso país. Muitos esqueceram das dores que outros tantos sofreram para estarmos aqui hoje, livres, falando sobre isso. Um tempo que se pararmos para lembrar não está tão longe assim dos dias atuais, mas é certo que a sua lembrança ainda dói na memória.

Palavras-Chave: Vladimir Herzog; Patética; Glauco Horovitz; ditadura militar; censura

\section{Abstract}

This paper aims to bring to reflection and to analyze naturalized Brazilian journalist Vladimir Herzog's life story, his personal and professional trajectory, and his cruel death in DOI-CODI's basements during the Brazilian military dictatorship (1964-1985). His death is the main conflict of Patética, a dramaturgic text censored by the military. Written by João Ribeiro Chaves Neto, brother-in-law to Vladimir Herzog, the play unravels, through metaphors, the sad history of the journalist murdered by the military regime. This paper presents a view on Herzog's and Chaves Neto's biographies, as well as on Patética's trajectory throughout its censorship. It is important to clarify this paper holds its character of historic elaboration and does not intend to analyze the text itself, as it affiliates to the field of Brazilian theatre history, focused on the discussion of the censorship that affected a large part of the Brazilian artistic movement and on the violence that Brazilian people have been subject to during the so-called "lead years". The methodology here applied involved searching through many biographies the story this article looks for and crossing facts and opinions on the subject. It concludes that there still is certain conformity concerning Brazil's collective memory, as many have forgotten the pain so many others have suffered to pave the way so that the people could even discuss freely this very subject. A time that passed not that long ago, and whose memory still hurts deep.

Palavras-Chave: Vladimir Herzog; Patética; Glauco Horovitz; Brazilian military dictatorship; censorship

ISSN: $1808-3129$

$1 \quad$ Universidade do Estado de Santa Catarina, Brasil jonatagoncalvess@gmail.com 


\section{Introdução}

Falar sobre o teatro brasileiro pode configurar uma enorme dissertação sobre nossas origens culturais até os dias contemporâneos. Embora, quando comparamos sua trajetória com culturas de outros povos e nações, o teatro brasileiro se torna uma história relativamente jovem que abrange uma série de fatos, crises, avanços e mudanças. Fatos esses que por vezes foram traumáticos, doloridos e em outros casos revigorantes e enriquecedores. Falar sobre o teatro feito no Brasil é falar das pessoas que colaboraram para a sua reinvenção a cada período. Enfim, falar dessa nobre arte dentro do contexto brasileiro é também buscar a compreensão de alguns casos marcantes dessa trajetória sociocultural do país.

É sobre isso, portanto, que falo neste artigo. De um período em particular que o teatro agiu e reagiu valentemente sob a pressão militar. Um tempo em que mesmo debaixo de duras leis contra não só as diversas manifestações culturais, mas também contra a livre expressão, foi um tempo de experimentação artística, distinto e nacionalista em sua essência. Com este artigo proponho uma rápida análise sobre um recorte específico entre esses anos de chumbo. Mais especificamente sobre o caso da censura que o texto Patética, de João Ribeiro Chaves Neto, obteve na época em que ganhou o VIII Concurso Nacional de Dramaturgia de 1976 e toda a polêmica que ele levanta a respeito da morte do jornalista Vladimir Herzog no ano anterior.

\section{O início de tudo, o caso Herzog}

Nascido em 27 de junho de 1937 em Osijek, na antiga lugoslávia e atual Croácia, passou a se chamar Vladimir quando se naturalizou brasileiro. Mais tarde, ao assinar o formulário que lhe garantia a carteira de identidade de estrangeiro escreveu apenas Vlado. E assim ele era conhecido pelos amigos e familiares.

Concebido em um berço tradicionalmente judeu, filho de Dona Zora e Seu Zigmund, Vlado já conheceu uma das faces, talvez a mais perversa do homem, quando muito jovem, sua família teve que entregar forçadamente sua casa para os soldados alemães que estavam tomando o território europeu durante a Segunda Guerra Mundial. Além do seu lar, os alemães também tomaram a empresa de seus pais, uma loja familiar de porcelanas e outros produtos. Este ato os obrigou a fugirem de Osijek para a Itália. Inicialmente auxiliados por um oficial alemão que fazia tráfico de refugiados, os Herzog pularam de cidade em cidade, fugindo do ódio nazista pelo seu povo, até que, em 1946 a família decidiu se refugiar no Brasil.

Aqui, nesse país tropical, exótico e por isso mesmo menos refinado para onde a sua família veio, Vlado foi criado. De acordo com jornalista Paulo Markun em seu livro Meu querido Vlado: a história de Vladimir Herzog e do sonho de uma geração (2005), em 1959 ele ingressou de cabeça no jornalismo quando iniciou suas atividades no Estadão, principal centro da efervescência jornalística do país. No ano seguinte, Vladimir foi incluído na equipe enviada para realizar a cobertura da inauguração de Brasília. Diferentemente de seus outros colegas que esbanjavam o entusiasmo juvenil de participar de tal ato histórico, o convívio com os cartolas e políticos de alto escalão não era o que, aparentemente, agradava Vlado. 
Outro importante fato que se tornaria primordial para a mudança de relação entre Vlado e o nosso país foi a passagem do filósofo francês Jean-Paul Sartre em setembro de 1960. Novamente o Estadão cobriu amplamente a sua estada no Brasil e foi através das falas existencialistas de Sartre, da sua filosofia ao tratar de assuntos de conflitos sociais, que Vlado descobriu o engajamento político-social. (MARKUN, 2005).

Embora exercendo a função de chefe de redação dentro do veículo de comunicação, Vlado acreditava em outro tipo de jornalismo, mais humano e por isso mais verdadeiro. Quando foi enviado para Mar del Plata, no Uruguai, para cobrir o festival de cinema conheceu aquele que seria um guru do cinema, pregando uma verdade que ele tanto procurava. Sua amizade com o cineasta argentino Fernando Birri se estendeu por muitos anos e mútuas eram suas admirações um pelo outro. Desse contato, Vlado chegou a planejar um documentário sobre Canudos e Antônio Conselheiro, porém seu único trabalho finalizado dentro desse formato de cinema verdade foi um curta-metragem chamado Marimbás. “Dez minutos retratando a vida dos deserdados que viviam das sobras deixadas na praia pelos pescadores de Copacabana, ao limpar as redes", (MARKUN, 2005, p. 31). Acredito que, muito provavelmente, essa verdade que Vlado procurava era um reflexo do que ele e sua família deixaram para trás no velho continente e o que ele ainda buscava em terras tupiniquins. Foucault comenta sobre essa busca da verdade e o seu significado:

A "verdade" está circularmente ligada a sistemas de poder, que a produzem e apoiam, e a efeitos de poder que ela induz e que a reproduzem. "Regime" da verdade. [...] O problema não é mudar a "consciência" das pessoas, ou o que elas têm na cabeça, mas o regime político, econômico, institucional de produção da verdade, (FOUCAULT, 1979, p. 14).

Ao observar sua trajetória e as escolhas que fez é possível de afirmar que Vlado acreditava nisso! Acreditava na força social transformadora quando trabalhava neste campo do jornalismo, ou mesmo do cinema. Tomando como referência os escritos de Paulo Markun (2005), em 1963 Vlado começou a trabalhar em outro tipo de veículo de comunicação: a TV. O programa se chamava Show de Notícias na extinta TV Excelsior e ele exerceu a função de coordenador de produção. Nesse mesmo ano, Vlado conheceu a pessoa que seria futuramente reconhecida por todos pela sua força e dedicação: Clarice Ribeiro Chaves era colega de um amigo seu no curso de Ciências Sociais da USP. O namoro foi rápido e se casaram em 15 de fevereiro de 1964.

Pouco tempo depois aconteceu o Golpe Militar. O fatídico acontecimento, inicialmente não tão cruel como foi a posteriori, deixou a todos um tanto atordoados e perdidos. "Agitada no entrechoque das ideias e das paixões, no expressar dos seus pensamentos, a nação adormeceu livre no dia 30 de março de 1964 e acordou na madrugada do dia 31 com botas militares sobre a cabeça do seu povo, e dela só as retirando 21 anos depois", (ALMEIDA, 2007, p. 323). Insatisfeito com os rumos que o seu país tomava e através de um contrato feito com o Serviço Brasileiro da BBC de Londres, o jornalista e amigo de Herzog Paulo Markun nos conta em seu livro que em 1965 Vlado decidiu partir para a Inglaterra juntamente com outros jornalistas. Seis meses mais tarde, Clarice também o encontrou em Londres. Sua ida para a Grã-Bretanha não configurou para Vlado como um exílio, muito pelo contrário. Vlado lá 
trabalhava como produtor e locutor, colaborando também ao Departamento de Cinema e TV. Além disso, também estudou cinema e televisão cursando como bolsista indicado pela Secretaria de Educação de São Paulo. Lá a sua família aumentou. Foi em solos monárquicos que nasceram os seus dois filhos: Ivo e André.

O jornalista e sua família passearam por outras cidades da Europa e as matérias que Vlado enviava para a revista Visão "[...] inscreveram seu nome no pedido de busca secreto número 168, expedido pela Divisão de Segurança e Informações do Ministério da Justiça em 20 de dezembro de 1967", (MARKUN, 2005, p. 33). Este documento solicitava mais detalhes da vida e das atividades dos jornalistas colaboradores da revista sob a suspeita de serem comunistas ou estarem ligados às atividades esquerdistas. Em nome da Segurança Nacional o governo militar realizou muitas ações coercitivas, repressivas e terríveis foram os resultados. Agassiz Almeida, explica um pouco sobre isso:

No Estado militar, a segurança nacional transveste-se numa verdadeira mística. Uma simples reunião, qualquer movimento sindical, estudantil ou mesmo religioso, ato ou escrita que não obedeça à ordem estabelecida de acordo com a "segurança nacional”, desperta reações dos órgãos de repressão. (ALMEIDA, 2007, p. 181)

Em agosto de 1968 a família de Vladimir Herzog retornou ao Brasil. Ele continuou em Londres terminando os seus estudos. No mês de dezembro, numa sexta-feira 13, foi decretado o Ato Institucional №5 (Al-5). O mais ditatorial dos decretos dentro do regime militar brasileiro que atingia diretamente (por meio da censura) jornalistas e pessoas do ofício artístico. $O$ ato encerrou qualquer tipo de liberdade artística ou por parte da imprensa e acabou com os direitos dos brasileiros. Vlado demorou três semanas para retornar ao Brasil após esse triste evento. Teve dificuldades de ingressar no mercado jornalístico por conta das suspeitas com a sua inclinação esquerdista, porém conseguiu se manter na revista Visão como editor cultural. Somente em 1972 Vlado foi chamado para secretariar o recém-lançado Hora da Notícia, um telejornal diário feito na TV Cultura. Porém, sentia-se insatisfeito diante da cobertura obrigatória dos atos do governo. Somente mais tarde, quando assumiu o cargo de diretor do Departamento de Telejornalismo da TV Cultura, foi quando ele finalmente pôde trabalhar naquilo que realmente acreditava na sua profissão. De acordo com Fernando Pacheco Jordão:

[...] fazer Jornalismo, para ele, era informar e discutir a sua época e nisso empenhava toda a sua integridade e honestidade profissional. Colocava, acima de qualquer interesse paralelo, a responsabilidade social de sua profissão e por isso era rigoroso ao extremo no trabalho, consigo mesmo e com os colegas, (JORDÃO, 2005, p. 208).

Nesses tempos difíceis e pouco amistosos de pessoas com ideais sociais, qualquer tipo de pensamento fora do enquadramento ditado pela Segurança Nacional era considerado uma ameaça comunista. Assim como foram algumas opiniões contra a nova cartilha que Vlado queria implantar dentro do jornalismo da TV Cultura. Surgiram comentários que o comunismo estaria infiltrado dentro da emissora. Por conta disso, o jornalista foi procurado na TV por dois agentes do Estado solicitando a sua presença no DOI-CODI (Destacamento de Operações de Informações - Centro de Operações de Defesa Interna), para prestar alguns esclarecimentos. Curiosamente houve uma ne- 
gociação e Vlado pôde se apresentar no dia seguinte. Portanto, como prometido, na manhã daquele sábado no dia 25 de outubro de 1975, Vladimir Herzog se apresentou espontaneamente nas dependências do DOI-CODI em São Paulo. Naquele mesmo dia, à tarde, já estava morto. Lá, o jornalista foi interrogado, torturado e assassinado pela suposta ligação com o Partido Comunista Brasileiro. Nos porões da repressão, antes de arrancarem a sua vida, forçaram Vlado a assinar uma declaração onde ele estaria confirmando a acusação de ligação ao partido, mas ele se negou em colaborar com esse plano. Sob a chancela do Estado, Vlado, assim como tantos outros, sofreu agressões físicas e morais. Agassiz Almeida fala um pouco sobre esse ato terrível da tortura:

O que monstrualiza a tortura difamante não é a ação de um homem em relação a outro, nem de um grupo social contra o seu ex-adversus. Não. O que nos estarrece é que este crime foi ato legitimado pelo próprio Estado, ou seja, decisão governamental com apoio explícito ou tácito de órgãos e instituições estatais, (ALMEIDA, 2007, p. 272).

Prontamente após esse terrível episódio, no mesmo dia, o comando do II Exército informava que Vladimir Herzog, depois de ter confessado a sua ligação com o Partido Comunista Brasileiro e com a KGB havia se suicidado. Tal absurda declaração deu início a um longo capítulo em busca da verdade dos fatos. De um lado estavam os militares que forjaram provas, laudos médicos que comprovavam o suicídio e a suposta confissão assinada pelo próprio Vlado. Do outro, a viúva Clarice e amigos do jornalista que nunca aceitaram a história pintada pela ditadura e denunciaram o seu assassinato. $O$ jornalista Rodolfo Osvaldo Konder, em seu depoimento, declarou o seguinte:

[...] podíamos ouvir nitidamente os gritos, primeiro do interrogador e, depois, de Wladimir, e ouvimos quando o interrogador pediu que lhe trouxessem a "pimentinha" e solicitou ajuda de uma equipe de torturadores. Alguém ligou o rádio e os gritos de Wladimir confundiam-se com o som do rádio. Lembro-me bem que durante essa fase o rádio dava a notícia de que Franco havia recebido a extrema-unção, e o fato ficou gravado, pois naquele mesmo momento Wladimir estava sendo torturado e gritava. (KONDER apud ARNS, 1985, p. 258)

A morte de Vlado gerou uma comoção nacional. Não somente em seu enterro, infelizmente realizado às pressas sob pressão dos militares, como também no ato ecumênico que aconteceu dias depois na Catedral da Sé. Tal fato configurou-se como uma ode à liberdade e contra a repressão. A sociedade exigia um basta diante de tanta violência. Naquele dia, os principais veículos de comunicação de todo o país noticiaram que 8 mil pessoas estiveram em frente à Catedral, no centro da capital paulista, em solidariedade à família Herzog, aos muitos cidadãos presos e mortos, ao povo brasileiro amordaçado pela ditadura.

Vários capítulos se desenrolaram por anos para que a integridade de Vladimir Herzog fosse mantida. Família, amigos, colegas e admiradores do jornalista, cada um fez a sua parte para que a sua honra não fosse brutalmente assassinada, como fizeram com o seu corpo. Uma dessas ações ficou muito famosa, talvez não como se esperasse, por ter sofrido tamanha retaliação. Porém, sua força pungente até hoje é reconhecida. O texto teatral Patética foi um documento de denúncia que, infelizmente, teve um destino tão obscuro quanto Vlado. Sobre essa obra dramatúrgica irei detalhar no item a seguir. 


\section{A vida e obra de João Ribeiro Chaves Neto}

Talvez um dos mais emblemáticos fatos da história do teatro brasileiro durante a época da ditadura militar ao meu ver, foi a censura sofrida por João Ribeiro Chaves Neto, autor da obra Patética. Não só pelo tema que ela abordava, mas também pelo, no mínimo, estranho e peculiar processo ao qual ela foi submetida. O texto traz à tona, através de uma parábola, a vida e morte do cunhado do autor do texto, o jornalista Vladimir Herzog.

De acordo com Rodrigo Costa, que realizou uma grande pesquisa sobre o texto Patética e seu autor em seu trabalho de conclusão de curso pela UDESC (2011), João Ribeiro Chaves Neto nasceu em 16 de dezembro de 1946 dentro do seio de uma família da classe média paulistana. O pai era de origem portuguesa e construía casas e apartamentos. A mãe, de origem alemã, foi uma grande apreciadora das artes e de grande sensibilidade cultural. Chaves Neto tinha dois irmãos. Clarice, dois anos mais velha e Valdir, o caçula. Desde a sua infância já demonstrou sua inclinação para assuntos ligados à arte e cultura. No colégio participou de jograis onde realizou todas as funções necessárias para as montagens.

Ainda sob os estudos de Rodrigo Costa (2011), entre os 17 e 18 anos Chaves Neto prestou vestibular e passou a estudar direito na Universidade de São Paulo (USP), no campus do Largo do São Francisco. Assim que se formou, começou a trabalhar no Citybank. Rapidamente assumiu o cargo como um dos diretores da empresa. Totalmente mergulhado em assuntos mais burocráticos a vida que Chaves Neto tomou nesse período o forçou a ficar mais longe de seus ideais artísticos. Porém, entre os anos de 1966 e 1967, ele frequentou o grupo Casarão, onde fazia teatro nos períodos noturnos e aos finais de semana. A sede do grupo situava-se no bairro do Bexiga, próximo ao Minhocão. Nesse momento ele se encontrava muito animado em poder trabalhar com aquilo que ele realmente queria: o teatro.

João Ribeiro Chaves Neto, sempre teve uma inclinação natural para o teatro politicamente engajado. Não só pelo fato do seu cunhado ter sido morto nos porões do DOI-CODI, mas também por ter tido outro parente seu assassinado pelas mãos da ditadura. Seu tio, irmão da sua mãe, foi morto dentro de uma prisão durante o período do governo Getúlio Vargas. Mal sabia ele, mas a repressão e a censura seriam uma constante em sua vida. Um dos seus primeiros combates foi em 1968 quando o seu grupo tentou regularizar uma montagem que vinha há dois meses se apresentando clandestinamente. Era uma adaptação feita pelas próprias mãos de Chaves Neto da obra O Urso de Anton Tchekhov (1860-1904). A avaliação que a censura fez da adaptação foi terrível submetendo a ela vários cortes o que impossibilitou a continuação da montagem. Isso foi um choque duríssimo para o autor e o restante do elenco, cuja consequência foi enterrar a peça e a desistência de Chaves Neto em continuar a fazer teatro, (COSTA, 2011).

Em seguida, outro fato marcante iria mudar totalmente os caminhos da vida de João Ribeiro Chaves Neto: a cruel morte de Vladimir em 25 de outubro de 1975. Assumindo a sua revolta e indignação, no ano seguinte o dramaturgo escreveu a obra Patética. "[...] constituiu-se num pungente e nobre documento contra a violência, o desrespeito à dignidade humana, o abuso do poder", (MICHALSKI, 2004, p. 350). 
A obra apresenta, metaforicamente, a insólita jornada de Glauco Horowitz que, assim como Vladimir Herzog, fugiu ainda criança da lugoslávia com a sua família, adotando - Brasil como a sua pátria. Nesta terra, o protagonista da história que João Ribeiro Chaves Neto apresenta percorre a mesma trajetória de Herzog. De brilhante jornalista para mais um óbito provocado pela ditadura militar. Tudo isso é contado através da encenação de uma trupe de circo que vive o último espetáculo de sua decadente carreira. Ou seja, João Ribeiro Chaves Neto utilizou sua escrita como um manifesto contra o terrível fim imposto pela ditadura para com o seu cunhado. Para Yan Michalski:

\begin{abstract}
A linguagem de parábola de que o autor se valeu para contar a terrível história é especialmente adequada para ressaltar esse valor simbólico do fato verídico que inspirou a obra. [...] Ele mostra também, por exemplo, e de modo muito eloquente, como a violência cometida contra Herzog infiltrou-se irresistivelmente na vida das pessoas que com ele conviviam: sua mulher, sua mãe, seu cunhado (pois Chaves coloca-se a si mesmo em cena, sob o disfarce do personagem de Valdeir, também ele dramaturgo e autor de uma peça "escrita estritamente conforme os padrões da época”, (MICHALSKY, 2004, p. 350).
\end{abstract}

\title{
A peça 143
}

Yan Michalsky, no seu livro Reflexões sobre o teatro brasileiro do século XX (2004) nos conta que a peça de João Ribeiro Chaves Neto foi uma das 157 obras inscritas no VIII Concurso de Dramaturgia do Serviço Nacional do Teatro (SNT) no ano de 1976. Todos aguardavam pela divulgação do resultado em março do ano seguinte. Porém, quando a comissão julgadora entregou os seus pareceres no mês de janeiro de 1977 para o então diretor do órgão Orlando Miranda estava claro que a peça com o número de inscrição 143, no caso Patética, seria a premiada. Miranda então ficou preocupado em anunciar como campeã uma peça que falava justamente sobre o jornalista morto no ano anterior e que gerou tanto furor. Tal fato levou o diretor da SNT e o Ministro da Educação e Cultura, Ney Braga, a adiar diversas vezes a reunião final para somar as notas dos jurados e ratificá-las.

As evasivas respostas do diretor do SNT e dos membros do júri chegam a ser patéticas, na medida em que deixam clara a existência de um impasse em que todos estão envolvidos, e cuja solução não parece estar ao alcance de nenhum deles. Trocando em miúdos: o órgão oficial do Governo Federal encarregado dos assuntos teatrais organiza um concurso de dramaturgia. Em todas as edições anteriores do concurso os resultados traduziriam a opinião livre e soberana do júri. Desta vez, todos os prazos concedidos para o julgamento foram amplamente estourados. Os jurados terminaram a leitura e enviaram as suas notas há vários meses. Tudo indica, portanto, que o SNT já sabe quais são os textos vencedores. Mas a reunião final do júri não é convocada e os resultados não são divulgados. $\mathrm{O}$ diretor do órgão assume a sua impossibilidade de declarar os motivos do atraso, isenta a Censura de qualquer interferência e diz que está procurando ganhar tempo para evitar o sacrifício do concurso (MICHALSKY, 2004, p. 269)

Todo o lento processo de anúncio do vencedor do concurso gerou uma situação extremamente desconfortável entre os organizadores, sociedade artística, jornalistas e outras pessoas interessadas no resultado final. Até que, de acordo com o 
livro de Yan Michalsky (2004), vazou o número de inscrição da obra premiada: 143. Texto escrito pelo autor de codinome Botabô. Tamanha foi a pressão dos órgãos de comunicação e sociedade interessada que em 07 de outubro de 1977 foi marcada a tão esperada liberação do resultado do concurso. Sendo assim, como já era esperada, a peça inscrita sob o número 143 recebeu o maior número de votos, porém curiosamente sua homologação não pôde ser realizada, pois o envelope de identificação havia sido confiscado pelos órgãos de segurança. Nesse instante, Chaves Neto, que se encontrava naquele dia nas dependências do SNT manifestou-se profundamente emocionado bradando ser o autor da obra em questão. Em punho, o dramaturgo carregava o protocolo de inscrição comprovando a sua fala.

O circo, literalmente, foi armado. De um lado Chaves Neto, jurados e outros dramaturgos exigiam os direitos da premiação, assim como a divulgação do resultado e a publicação da obra. Do outro lado estava Orlando Miranda que, constrangido com a situação, tentava tecer desculpas incabíveis para o fato, (COSTA, 2011). Indignado com tal acontecimento, João Ribeiro Chaves Neto saiu do recinto e iniciou uma longa batalha contra a injustiça que acometiam o seu texto. Porém, não só João Ribeiro Chaves Neto sentiu na pele os duros cortes que a censura estabeleceu na produção artística nacional. Vários outros dramaturgos tiveram também os seus textos impedidos de serem montados ou, se liberados, foram foiçadas palavras, frases, sentenças que apagavam o seu potencial artístico. Muitos atores e atrizes foram perseguidos, produções inteiras canceladas e teatros invadidos e/ou destruídos. Mas a luta nunca parou. O teatro brasileiro conseguiu manter-se fecundo dentro do possível. Sobre a censura sofrida pela produção artística, Cristina Costa reflete que:

[...] os mecanismos de censura, de um modo geral, são recursos do poder instituído para controle, fiscalização e sujeição dos artistas e da produção artística. Cria-se um órgão de controle de natureza burocrática e impessoal que age através de regulamentação explícita e implícita, e rotinas, em nome da sociedade e, sob o pressuposto de sua defesa. Esses mecanismos podem estar direcionados para a produção artística, para a indústria cultural, para os meios de comunicação de massa e para diferentes formas de divertimento como cassinos e cabarés. Podem também recair sobre a obra ou espetáculo quando levadas ao público ou podem ocorrer de forma prévia, ou seja, acompanhar o projeto de elaboração do espetáculo. (COSTA, 2006, p. 141)

Em 1978 foi realizada a primeira audiência para o depoimento de testemunhas e apresentação de provas numa ação cível que Clarice Herzog movia contra a União, desde abril de 1976, para responsabilizá-la pela prisão ilegal, pelas torturas e pela morte de seu marido. Foi a primeira vez na história do país que a União era responsabilizada judicialmente por tal ato. Em novembro do mesmo ano, o tão enigmático envelope com a inscrição de Patética apareceu nas dependências do SNT. Finalmente o resultado é homologado e o autor premiado, porém sua obra é imediatamente censurada e proibida a sua publicação e montagem.

Durante esse período Chaves Neto recebeu uma nova proposta do Citybank para trabalhar no Rio de Janeiro e lá assumir suas funções profissionais dentro da empresa. "[...] logo começou a fazer teatro no antigo casarão da UNE, na Praia do Flamengo, outro foco de resistência ao regime militar", (COSTA, 2011, p. 49). Lá, junto 
de outros artistas, ele escreveu outro texto chamado Caçamba Caxangá. Os ensaios desse novo espetáculo foram cancelados quando a UNE decidiu realizar a montagem do espetáculo proibido pela censura Eles não usam Black-Tie, de Gianfrancesco Guarnieri (1934-2006). Essa ocasião seria, mais uma vez, um golpe contra as suas produções artísticas. Ainda de acordo com Rodrigo Costa (2011), tais decepções foram gerando no autor algumas perturbações de humor e de personalidade. Chaves Neto se sentia frustrado diante de tudo isso. Amigos e familiares começaram a perceber em Chaves Neto problemas de ordem psíquica. Suas lutas, desde a infância, foram sempre atravessadas por decepções muito fortes e isso começou a refletir em seu comportamento.

O teatro foi o grande alvo de toda a censura. Talvez por ser uma arte que tem esse potencial de acontecer no momento presente, seja tão pungente sua comunicação com o público. E era disso que os militares tinham medo. O país sente até hoje essas perdas dentro da sua produção, porém temos que admitir que foi também uma época em que os artistas tinham que saber "driblar" a censura e, sendo assim, serem mais criativos ao colocar na cena, entre linhas, seus ideais e questionamentos contra toda a repressão que sofriam. Quanto a esse golpe contra as artes cênicas brasileiras, Yan Michalsky analisa da seguinte forma:

Realmente, o empobrecimento foi inegável e muitas iniciativas poderiam ter contribuído para o progresso do teatro brasileiro foram cruelmente sufocadas. [...] Entretanto, hoje é legítimo constatar que, paradoxalmente, esse teatro amordaçado produziu uma das etapas mais fecundas da sua história. Poucas vezes surgiram, em 20 anos, tantas obras inspiradas, tantos generosos impulsos de renovação, tantas corajosas decisões de dizer "não" - e é quase sempre dizendo "não" que o teatro costuma alçar o seu voo mais alto. (MICHALSKY, 2004, p. 8)

Somente na década de 1980, dirigida pelo famoso encenador Celso Nunes, Patética foi finalmente liberada para a montagem e apresentação. Sua estreia foi no Teatro Augusta em São Paulo. A peça confirmou a sua grandiosidade dramatúrgica e a potencialidade de seu autor. Nunes conseguiu extrair toda a emoção e sensibilidade que o texto pedia, porém a recepção do público não foi a mais calorosa. Em tempos de novas aberturas políticas o público demonstrava-se relativamente cansado com espetáculos engajados em uma luta ainda ligada à década passada. Tal resultado só comprovou as terríveis mazelas deixadas pela censura na produção teatral brasileira. "[...] se Patética pudesse ter sido representada dentro do contexto histórico que lhe deu origem, ela seguramente teria provocado um impacto bem diferente daquele que suscitou alguns anos depois", (MICHALSKY, 1985, p.86).

Quanto a Chaves Neto, seu estado de saúde mental foi agravado quando em meados dos anos 1980 descobriu ser portador do vírus HIV. Profundamente abalado, o dramaturgo retorna para São Paulo onde passou algum tempo sob os cuidados da mãe na cidade de Bragança Paulista. Fortalecendo-se ao lado da família decide retornar para o estado do Rio de Janeiro, porém agora vai morar em um chalé na região serrana, na cidade de Nova Friburgo. Depois de algum tempo, e com o agravamento da doença, retornou para São Paulo onde faleceu entre os anos de 1992 e 1993. 


\section{Justiça, finalmente}

Quando Clarice Herzog entrou com a ação cível contra a União em outubro de 1978, o corajoso juiz Márcio José de Moraes foi categórico em sua declaração indenizando os danos materiais e morais em decorrência ao assassinato de Vladimir Herzog. Porém, a busca da viúva nunca foi pela consolação financeira, mas sim pela honra de seu marido. Provar que Vlado não tinha se suicidado, enforcando-se com o seu próprio cinto, mas sim cruelmente torturado até a morte. "É preciso primeiro lembrar que, entre todas as virtudes, a da justiça é a que, por excelência e por constituição, é voltada para outrem. [...] O dever de memória é o dever de fazer justiça, pela lembrança, a um outro que não o si", (RICOER, 2007, p. 101).

Somente em março do ano de 2013 a família Herzog recebeu do governo brasileiro o novo atestado de óbito apontando como causas da morte do jornalista lesões e maus-tratos. Porém, ainda falta determinar quem foram os seus algozes.

A Lei da Anistia, assinada pelo então presidente João Figueiredo em 28 agosto de 1979, desculpou a todos que cometeram crimes políticos ou crimes eleitorais, além dos que tiveram seus direitos políticos suspensos. Infelizmente, acabou anistiando também os repressores que foram responsáveis por muitas mortes e desaparecimentos de presos políticos. Agassiz Almeida traz alguns dados desse período:

\footnotetext{
Apontemos o quadro devastador com as informações e dados hoje disponíveis: cerca de 120 mil pessoas passaram pelas prisões; aproximadamente 40 mil foram submetidas a torturas de todos os tipos; cerca de 500 militantes mortos pelos órgãos repressivos, incluindo 152 "desaparecidos"; dezenas de baleados em manifestações públicas, com uma parte incalculável de mortos; 11 mil indiciados em processos judiciais por crimes contra a segurança nacional; centenas condenados à pena de prisão; 130 banidos e milhares se exilaram; 780 tiveram seus direitos políticos cassados por dez anos, com base em atos institucionais; incontáveis aposentadorias e demissões do serviço público, decretadas por atos discricionários. (ALMEIDA, 2007, p. 360)
}

É importante salientar que passo a passo o povo brasileiro vai tomando o real conhecimento dos fatos e aprendendo com a sua história. Em 18 de novembro de 2011 a presidente Dilma Rousseff sancionou a lei que instituiu a formação da Comissão Nacional da Verdade. Essa comissão teve o objetivo de levantar dados, documentos, entrevistar acusados e vítimas da repressão entre os anos de 1946 e 1988. Ivo Herzog (filho de Vladimir), fundou em 25 de junho de 2009 o Instituto Vladimir Herzog, uma Organização da Sociedade Civil de Interesse Público (OSCIP) que tem como objetivo a proteção de profissionais da imprensa de violências cometidas contra eles em função do desempenho da sua profissão. Além disso, o Instituto mantém viva a memória do Vlado através de prêmios às produções jornalísticas e apoia também outros materiais, como: revistas, filmes e outras publicações.

Escrita em 1976, Patética teve pouquíssimas montagens dentro do território nacional. Mais recentemente, em agosto de 2011, um grupo teatral da cidade de Itajaí (SC) estreou sua montagem do texto. O grupo llustríssimos Senhores trouxe à tona a história da vida de Glauco Horowitz servindo como documento, denúncia e atestado de um duro episódio da nossa história. Com direção de Rafael de Melo, o grupo ita- 
jaiense manteve a força e pungente da peça que reafirma o valor do autêntico teatro brasileiro como expressão lúcida das crises e angústias de nosso povo.

As vidas e obras de Vladimir Herzog e João Ribeiros Chaves Netos estarão, para sempre, a nos impulsionar e motivar. Pelo menos, enquanto houver a verdade... e a arte.

\section{Referências}

ALMEIDA, Agassiz. A ditadura dos generais: estado militar na América Latina: o calvário na prisão. 2 ed. Rio de Janeiro: Bertrand Brasil, 2007.

ARNS, Dom Paulo Evaristo. Brasil: nunca mais. Petrópolis: Vozes, 1985.

COSTA, Cristina. Teatro, comunicação e censura. São Paulo: Edusp, 2006.

COSTA, Rodrigo. Patética: do contexto ao texto. 2011. 89 p. Trabalho de conclusão de curso superior em Educação Artística com habilitação em Artes Cênicas. UDESC, Florianópolis.

FOUCAULT, Michael. Microfísica do poder. Organização e tradução de Roberto Machado. Rio de Janeiro: Graal, 1979.

JORDÃO, Fernando Pacheco. Dossiê Herzog: prisão, tortura e morte no Brasil. 6 ed. São Paulo: Global, 2005.

MARKUN, Paulo. Meu querido Vlado: a história de Vladimir Herzog e do sonho de uma geração. Rio de Janeiro: Objetiva, 2005.

MICHALSKY, Yan. O teatro sob pressão: uma frente de resistência. Rio de Janeiro: Jorge Zahar, 1985.

MICHALSKY, Yan. Reflexões sobre o teatro brasileiro do século XX. Rio de Janeiro: Edusp, 2004.

RICOER, Paul. A memória, a história, o esquecimento. Tradução de Alain François [et al.]. Campinas: Unicamp, 2007. 